\title{
CLIMATE APPLICATIONS IN A VIRTUAL RESEARCH ENVIRONMENT PLATFORM
}

\author{
GEORGI GADZHEV* IVELINA GEORGIEVA* KOSTADIN GANEV* VLADIMIR IVANOV* NIKOLAY MILOSHEV* \\ HRISTO CHERVENKOV $\dagger$ AND DIMITER SYRAKOV ${ }^{\dagger}$
}

\begin{abstract}
Previous atmospheric composition studies were based on extensive computer simulations carried out with good resolution using up-to-date modelling tools and detailed and reliable input data.

The oncoming climate changes will exert influence on the ecosystems, on the all branches of the international economy, and on the quality of life. Regional climate models (RCMs) are important instruments used for downscaling climate simulations from Global circulation models (GCMs).

The air quality (AQ) impact on human health and quality of life is an issue of great social significance. Evaluating this impact will give scientifically robust basis for elaborating efficient short term measures and long term strategies for mitigation of the harmful effects of air pollution. The AQ impact is evaluated in the terms of Air Quality Indices (AQI). Some extensive numerical simulations of the atmospheric composition fields in Bulgaria and Sofia have been recently performed. A quite extensive data base was created from simulations which were used for different studies of the atmospheric composition, including the AQ climate.

Main aims of the numerical experiment presented in this paper are: (1) Adaptation and tuning of the RegCM model for the Balkan Peninsula and Bulgaria and thus development of a methodology able to predict possible changes of the regional climate for different global climate change scenarios and their impact on spatial/temporal distribution of precipitation, hence the global water budgets, to changes of the characteristics and spatial/temporal distribution of extreme, unfavorable and catastrophic events (drought, storms, hail, floods, fires, sea waves, soil erosion, etc.). (2) Development of a methodology and performing reliable, comprehensive and detailed studies of the impact of lower atmosphere parameters and characteristics on the quality of life (QL) and health risks (HR) for the population.
\end{abstract}

Key words: Virtual Research Environment, Regional climate models, RegCM, Air Quality Indices

AMS subject classifications. $86 \mathrm{~A} 10,65 \mathrm{Y} 05$

1. Introduction. The climate modelling community has very strong computational needs. In particular, the integration of various computational resources such as High-performance computing (HPC) and Grid jointly with data infrastructure. VI-SEEM is a project that aims at creating a unique Virtual Research Environment (VRE) in Southeast Europe and the Eastern Mediterranean (SEEM), in order to facilitate regional interdisciplinary collaboration, with special focus on the scientific communities of Life Sciences, Climatology and Digital Cultural Heritage. In the frame of the VI-SEEM project, the existing e-Infrastructures are being unify into an integrated platform to better utilize synergies, for an improved service provision within a unified Virtual Research Environment to be provided to scientific communities of high impact in the combined South East Europe and Eastern Mediterranean region. Perhaps the largest focus is on regional climate modelling and weather forecasting, where local weather and regional climate phenomena are investigated. This is complemented by global climate modelling where the impact of global phenomena on the regional climate is the focus. These results are crucial to predict extreme weather in the region and understand the future trends of the regional climate. Another strong field of related research is the study of air pollution that includes the influence on the climate and human health. These activities jointly enable the assessment of the impact on regional climate due to climate change. Climate impact studies provide the analysis of the upcoming change on humans, the environment and society that is so crucial for policy makers.

In this paper we will be present the results from two applications - ACIQLife (Atmospheric Composition Impact on Quality of Life and Human Health) and TVRegCM (Tuning and Validation of the RegCM) in the frame of VI-SEEM project, climate section.

The ACIQLife application is focused on development of a methodology and performing reliable, comprehensive and detailed studies of the impact of lower atmosphere parameters and characteristics on the quality of life (QL) and health risks (HR) for the population in our country. The TVRegCM reached to adaptation

\footnotetext{
*National Institute of Geophysics, Geodesy and Geography-Bulgarian Academy of Sciences, Acad. G. Bonchev str., bl. 3 1113 Sofia, Bulgaria (ggadjev@geophys.bas.bg),

${ }^{\dagger}$ National Institute in Meteorology and Hydrology-Bulgarian Academy of Sciences, 66, Tsarigradsko Shose blvd 1784 Sofia, Bulgaria
} 
TABLE 2.1

Computer resource requirements on $16 C P U$-s for 1 Day simulation for ACIQLife

\begin{tabular}{|c|c|c|c|}
\hline & WRF & CMAQ and SMOKE & Total \\
\hline Time (h) & 3 & 2 & 5 \\
\hline HDD (GB) & 0.5 & 1 & 1.5 \\
\hline
\end{tabular}

TABLE 2.2

Computer resource requirements on 16 CPU-s for TVRegCM

\begin{tabular}{|c|c|c|c|}
\hline & 1 Month Simulation & x120 Months & x20 Cases \\
\hline Time $(\mathrm{h})$ & 6 & 720 & 14400 \\
\hline HDD $(\mathrm{GB})$ & 6 & 720 & 14400 \\
\hline
\end{tabular}

and tuning of the RegCM model for the Balkan Peninsula and Bulgaria and thus development of a methodology able to predict possible changes of the regional climate for different global climate change scenarios and their impact on spatial/temporal distribution of precipitation, hence the global water budgets, to changes of the characteristics and spatial/temporal distribution of extreme, unfavorable and catastrophic events (drought, storms, hail, floods, fires, sea waves, soil erosion, etc.). All these changes will have influence on the ecosystems and on practically all sectors of the economy and human activity and consequently on the quality of life.

2. HPC computing. The model simulations were performed day by day for two periods.

The computer resource requirements for the (WRF) Weather Research and Forecasting Model, (SMOKE) Sparse Matrix Operator Kernel Emissions Modeling System, (CMAQ) The Community Multiscale Air Quality Modeling System and RegCM, simulations are rather big [16] (Tables 2.1 and 2.2) and that is why the numerical experiments were organized in effective High-performance computing (HPC) environment. The simulations were organized in two separate jobs: one job for WRF simulations and one job for SMOKE, CMAQ and post-processing procedures. This makes the jobs run time for 6 days real time fairly reasonable for ACIQLife application and 3 months for TVRegCM application.

The calculations were implemented on the Supercomputer System Avitohol at IICT-BAS (Institute of Information and Communication Technologies-Bulgarian Academy of Sciences). The supercomputer consists of 150 HP Cluster Platform SL250S GEN8 servers, each one equipped with 2 Intel Xeon E5-2650 v2 8C $2600 \mathrm{GHz}$ CPUs and 64GB RAM per server. The storage system is HP MSA 2040 SAN with a total of 96 TB of raw disk storage capacity. All the servers are interconnected with fully non-blocking FDR Infiniband, using a fat-tree topology [1] and [2]. The needed libraries and programs were installed on supercomputer for proper functioning and working of models used in this study. The Avitohol system is a part of the Virtual Research Environment platform (VRE platform) built in the framework of the VI-SEEM project [3]. The both applications - ACIQLife and TVRegCM use not only HPC resources provided by the VRE platform, but they use also other services like VI-SEEM Simple Storage (VSS) and VI-SEEM Archival Service (VAS) to save the obtained data. The training materials about both applications are available in the VI-SEEM Training portal [4] and [5]. According the VI-SEEM accounting system [6], 730 ACIQLife jobs and 810 TVRegCM jobs were run to receive some of the current scientific results. The needed CPU time and storage per job is shown in the Tables 2.1 and 2.2.

The models output from ACIQLife and TVRegCM applications are uploaded on VRE repository website. The results are free and can be use by the scientific communities in the region. The workflows wre also created and uploaded for both applications.

The ACIQLife ouput is a NetCDF file with surface concentrations on an hourly basis of the most important pollutants (which are used for calculation of AQI) and annually/seasonally averaged hourly values of the different AQI value for the selected area.

The TVRegCM ouput is also NetCDF file, but for each month of the period and consist of daily and hourly averaged values of the meteorological parameters for the area of interest.

3. ACIQLife application. Some extensive numerical simulations of the atmospheric composition fields in Bulgaria and Sofia have been recently performed. Quite extensive data base has been created from the 


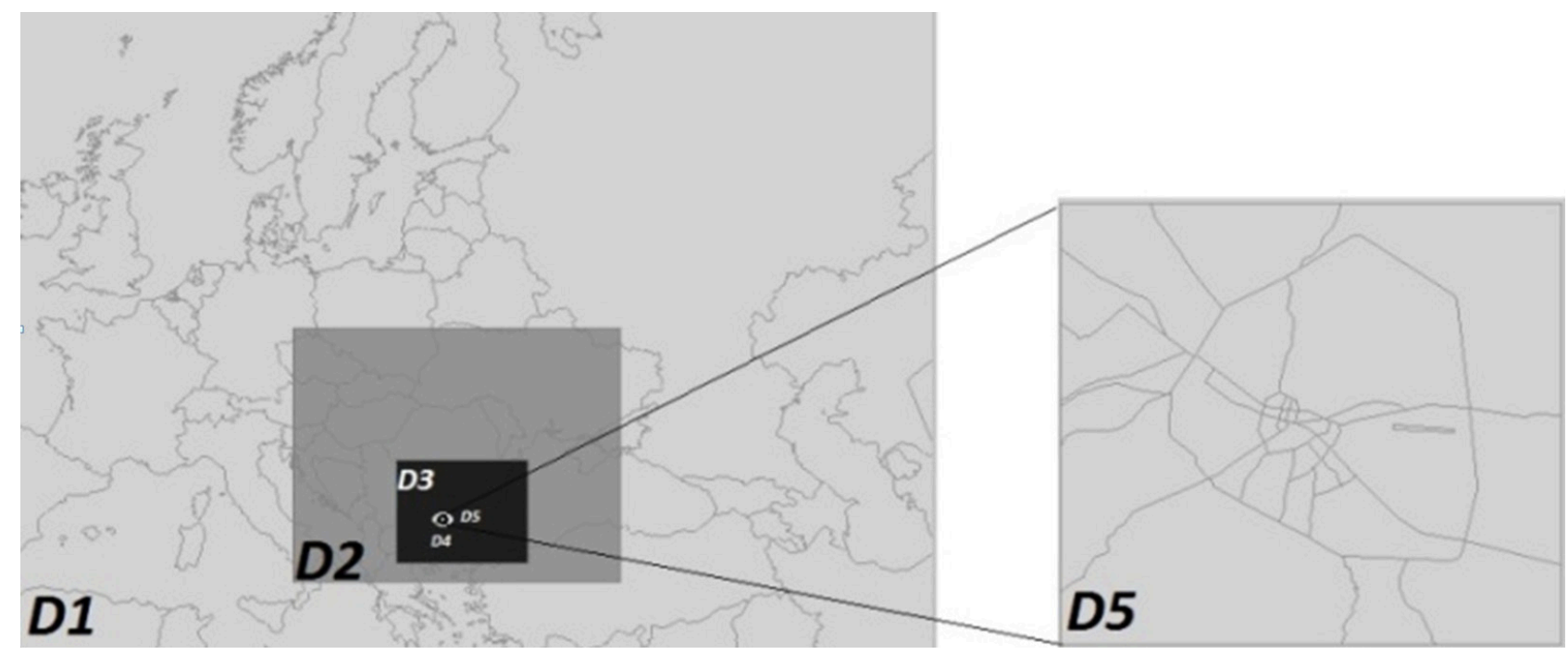

Fig. 3.1. Model domains - D1 $81 \times 81 \mathrm{~km}$ (Europe), D2 27×27 km (Balkan Peninsula), D3 9×9 km (Bulgaria), D4 3×3 km (Sofia region) and $D 51 \times 1 \mathrm{~km}$ (Sofia city).

simulations which is used for different studies of the atmospheric composition, including the AQ climate.

The atmospheric composition studies were based on extensive computer simulations carried out with good resolution using up-to-date modelling tools and detailed and reliable input data. All the simulations were based on the United States Environmental Protection Agency (US EPA) Model-3 system, which consists of 3 models: WRF [7] used as meteorological pre-processor; CMAQ [8, 9] and [10] - the Community Multiscale Air Quality System, being the Chemical Transport Model (CTM) and SMOKE [11, 12] - the Sparse Matrix Operator Kernel Emissions Modelling System - the emission pre-processor. The simulations were performed for 7 years period (2008 to 2014) with Two-Way Nesting mod on.

The large scale (background) meteorological fields, used by the application were taken from the National Centers for Environmental Prediction (NCEP) Global Analysis Data with $1^{\circ} \times 1^{\circ}$ resolution. The WRF and CMAQ nesting capabilities were used to downscale the simulations to a $9 \mathrm{~km}$ for domain D3 - Bulgaria and to a $1 \mathrm{~km}$ horizontal resolution for the innermost domain - Sofia. The simulations were carried out for 5 nested domains Figure 3.1. The used WRF model parametrizations and schemes are as follows: micro physics - WRF single moment 6-class, cumulus physics - Kain-Fritsch, boundary layer scheme - ACM2Pleim, surface physics - Pleim-Xiu Land Surface Model and the model vertical levels are 27.

The Bulgarian emission inventory was used as an emission input for Bulgaria, while outside the country the high resolution inventory of the the Netherlands Organization for Applied Scientific Research (TNO, see https://www.tno.nl/en/) with resolution $20 \times 15 \mathrm{~km}\left(0.25^{\circ} \times 0.125^{\circ}\right)$ was exploited. The latest one is produced by proper disaggregation of the European Monitoring and Evaluation Program (EMEP) 50-km data base [13, 14]. In both inventories the emissions are distributed over 10 Selected Nomenclature for Sources of Air Pollution (SNAP) categories [15].

The Air Quality is a key element for the well-being and quality of life of the European citizens and that is why the AQ impact on human health and quality of life is an issue of great social significance. The AQ impact on human health and quality of life is evaluated in the terms of Air Quality Indices (AQI), which give an integrated assessment of the impact of pollutants and directly measuring the effects of AQ on the human health. The evaluations are based on extensive computer simulations of the AQ for Bulgaria and Sofia city carried out with good resolution using up-to-date modelling tools and detailed and reliable input data $[16,17,18]$. All the AQI evaluations are on the basis of air pollutant concentrations obtained from the numerical modelling and make it possible to reveal the climate of AQI spatial/temporal distribution and behavior.The AQI is defined as a measure of air pollution and provides an integrated assessment of the impact of the pollutants on human health. The index is defined in several segments, each of which is a linear function of the concentration of each pollutant 
TABLE 3.1

Air Pollution Bandings and Index Impact on Human Health

\begin{tabular}{|c|c|l|}
\hline Banding & Value & Health Descriptor \\
\hline Low & $1-3$ & $\begin{array}{l}\text { Effects are unlikely to be noticed even by individuals who } \\
\text { know they are sensitive to air pollutants }\end{array}$ \\
\hline Moderate & $4-6$ & $\begin{array}{l}\text { Mild effects, unlikely to require action, may be noticed } \\
\text { among sensitive individuals. }\end{array}$ \\
\hline High & $7-9$ & $\begin{array}{l}\text { Significant effects may be noticed by sensitive individuals } \\
\text { and action to avoid or reduce these effects may be needed. } \\
\text { Asthmatics will find that their 'reliever' inhaler is likely to } \\
\text { reverse the effects on the lung. }\end{array}$ \\
\hline Very High & 10 & $\begin{array}{l}\text { The effects on sensitive individuals described for 'High' le- } \\
\text { vels of pollution may }\end{array}$ \\
\hline
\end{tabular}

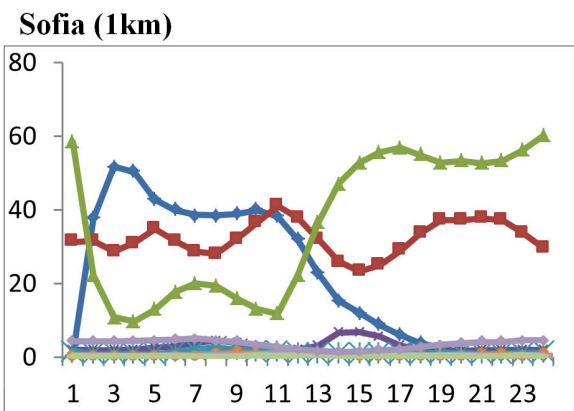

Bulgaria (9km)

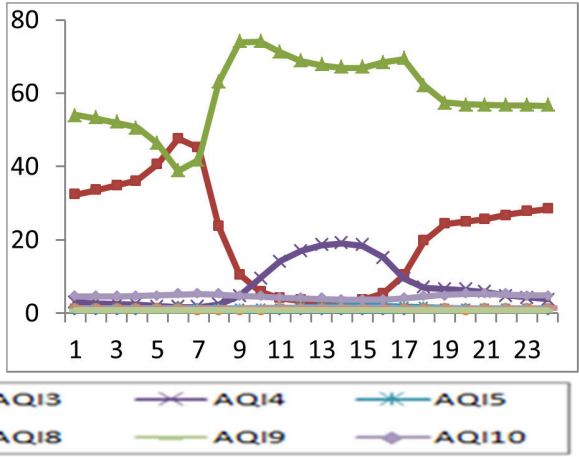

FIG. 3.2. Annual Diurnal variations [\%] of the different AQI (1 to 10) integrated over territory of Bulgaria and Sofia

considered [19]. The index falls in different ranges of the dimensionless scale. In each range the index values are associated with an intuitive color code ((from green to red), a linguistic description (e.g. from very good to very poor) and a health description. In order to evaluate the air quality situation in Europe, all measurements are transformed into a single relative figure: the Common Air Quality Index (CAQI) which has 5 levels using a scale from 0 (very low) to > 100 (very high). The index is based on 3 pollutants of major concern in Europe: Particulate matter, with diameter $<10 \mu \mathrm{m}$ (PM10), Nitrogen Dioxide $\mathrm{NO}_{2}$, Ozone $\mathrm{O}_{3}$ and will be able to take into account to 3 additional pollutants Carbon Oxide (CO), Particulate matter with diameter $<2.5 \mu m(\mathrm{PM} 2.5)$ and Sulphur Dioxide $\mathrm{SO}_{2}$. In different countries use different AQI on basis of different monitor pollutants.

The index, calculated in Bulgaria in the frame of Bulgarian Chemical Weather Forecast System [20, 21, 22], follows the United Kingdom (UK) Daily Air Quality Index [23]. This index has ten grades, which are further grouped into 4 bands: low, moderate, high and very high and is based on the concentrations of 5 pollutants $\mathrm{NO}_{2}, \mathrm{O}_{3}, \mathrm{SO}_{2}, \mathrm{CO}$ and PM10 (Table 3.1). Different averaging periods are used for different pollutants. The reference levels and Health Descriptor used in the tables are based on health-protection related limit, target or guideline values set by the European regulations, at national or local level or by the World Health Organization $[24,25]$.

Annually averaged hourly values of the AQI for Sofia and Bulgaria with different horizontal grid resolution are presented in Figure 3.2. The graphs represent the daily percent recurrence of the AQI (1 to 10). This results, allow to follow highest recurrence of the indices during the day (during the seasons), and to analyze the possible reason for high values in the High and Very High bands. The meteorological conditions from one hand and the pollutant emissions from other one could be the cause for different possible AQI statuses. That representation of the index makes it possible to evaluate the atmospheric composition in the context of impacts on human health and quality of life. 
Sofia

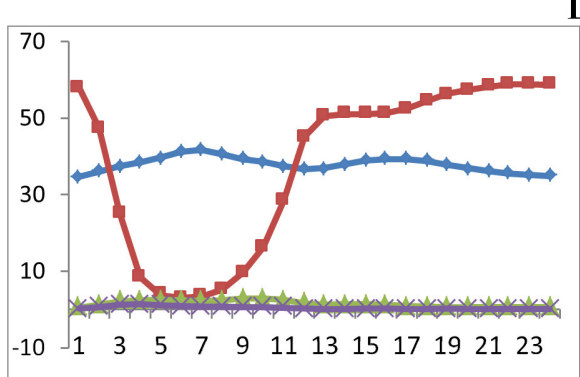

Bulgaria

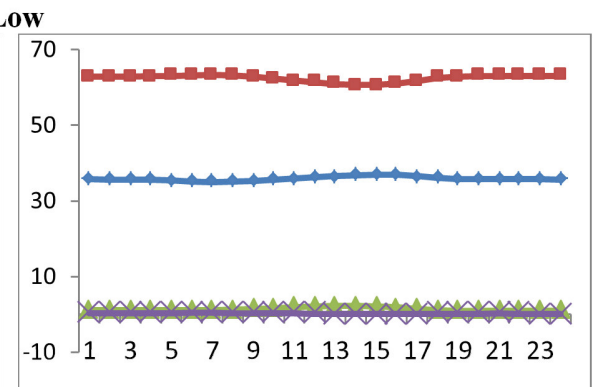

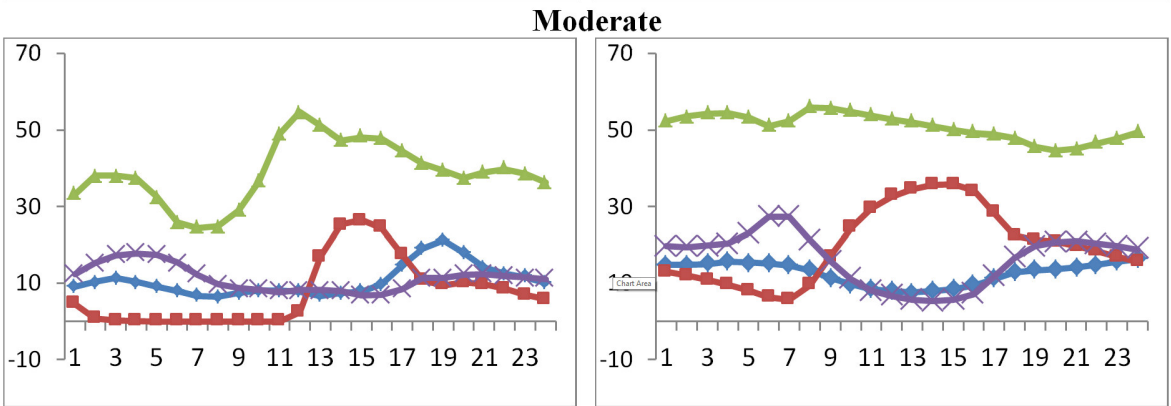

High
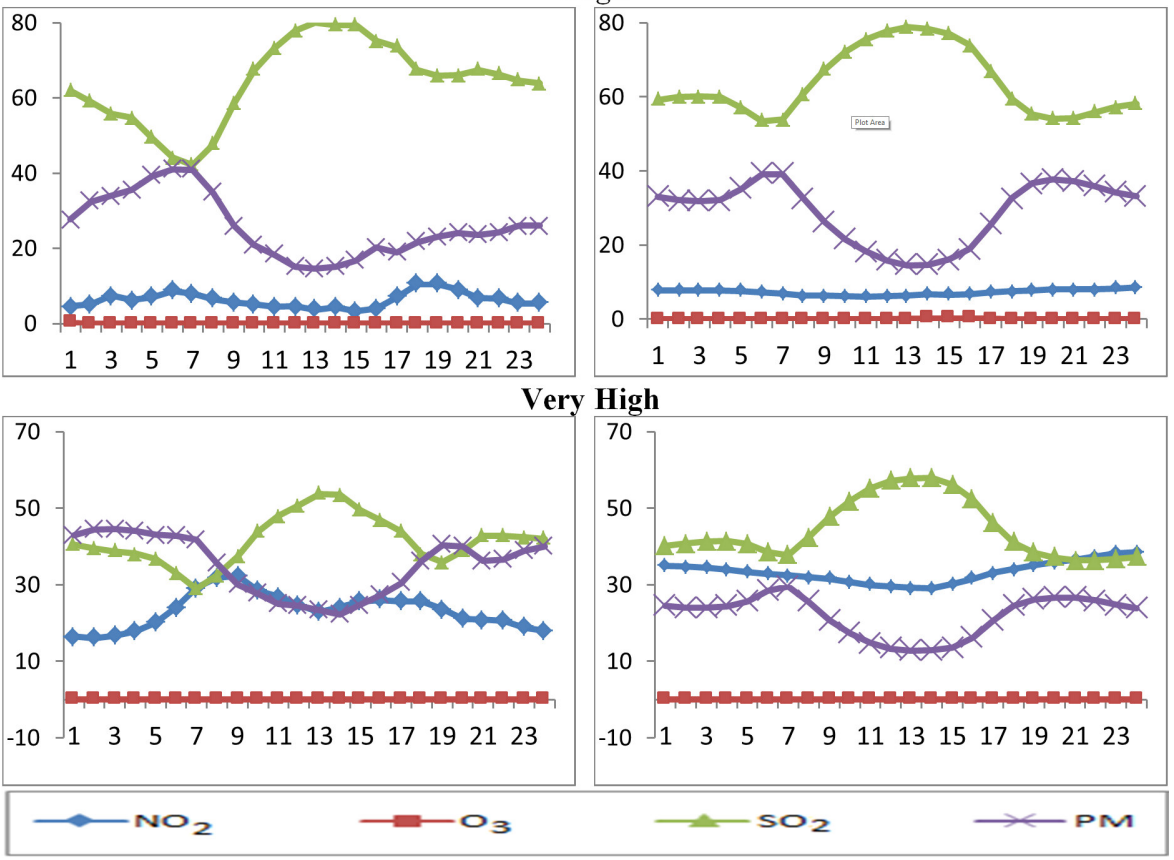

FIG. 3.3. Diurnal variations of the annually averaged recurrence [\%] of the dominant pollutant.

The graphics on Figure 3.3 demonstrate the annual recurrence of the pollutant with highest AQI, which determines the overall AQI for the 4 bands (the dominant pollutant). The pollutants involved in the calculation of AQI $-\mathrm{NO}_{2}, \mathrm{O}_{3}, \mathrm{SO}_{2}$ and $\mathrm{PM}$ are presented in different colours. The seasonal cases are not present here, but they differ from the annually averaged graphics. The dominant pollutants are different for each band with well displayed diurnal course.

The air pollution pattern is formed as a result of interaction of different processes, so knowing the contribu- 
NO2

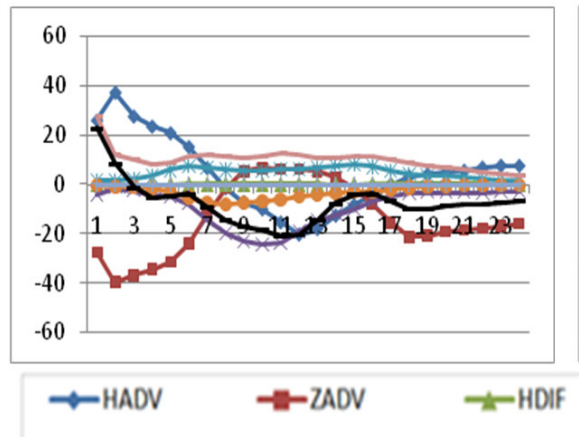

FPRM

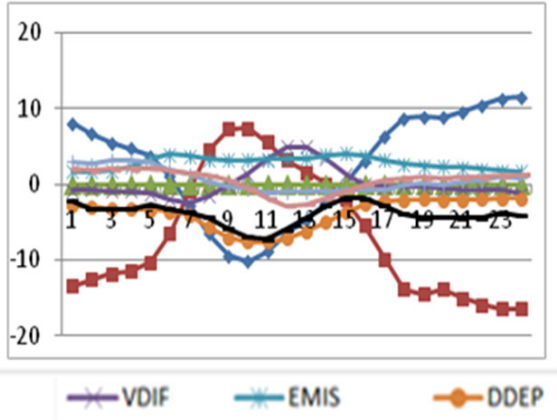

\section{CPRM}

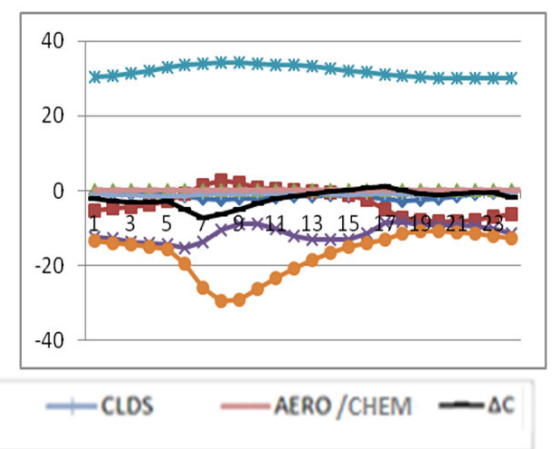

FIG. 3.4. Annually averaged contribution of the different processes to the formation of $\mathrm{NO}_{2}\left[\mu \mathrm{g} / \mathrm{m}^{3}\right]$ and FPRM, CPRM $[p P M v / h]$ for Sofia city.

tion of each one of these processes for different meteorological conditions and given emission spatial configuration and temporal behavior could be helpful for understanding the atmospheric composition formation and air pollutants behavior. Therefore the CMAQ "Integrated Process Rate Analysis" option was applied to discriminate the role of different dynamic and chemical processes for the air pollution formation. The procedure allows the concentration change for each compound for an hour $\Delta \mathrm{C}$ to be presented as a sum of the contribution of the processes, which determine the concentration. The results were averaged over the whole ensemble and so the "typical" seasonal and annual evaluations were obtained.

The diurnal/annual behavior of the processes contribution to the surface concentrations change of pollutant $\mathrm{NO}_{2}$, fine- and coarse particulate matter ( FPRM and CPRM), averaged for the territory of Sofia, is given in Figure 3.4.The considered processes are advection (horizontal - HADV - and vertical - VADV), diffusion (horizontal - HDIF - and vertical - VDIF), mass adjustment, emissions (EMIS), dry deposition (DDEP), chemistry (CHEM), aerosol processes (AERO) and cloud processes/aqueous chemistry (CLDS) and they are present in different colors.

The total concentration change $(\Delta \mathrm{C})$, leading to a change in a concentration is determined mainly by a small number of dominating processes which have large values, and could be with opposite sign and phases. The $\Delta \mathrm{C}$ is different for each pollutant with well displayed seasonal and diurnal course. The sign of the contributions of some of the processes is obvious, but some of them may have different sign and it depends on the type of emissions, weather conditions and local atmospheric dynamics.

4. Conclusion related to ACIQLife. A very small part of the obtained results is presented in the present paper, just to demonstrate the opportunity HPC platforms give for detailed and extensive study of the atmospheric composition its behavior, origin and health impact. Due to volume limitations the spatial variability of the air pollution characteristics is not demonstrated at all.

The generated ensembles of atmospheric composition characteristics have still to be carefully and extensively treated and analyzed, which will be objective of the future work of the authors.

5. TVRegCM application. The simulations with the RCM RegCM version $4.4[26]$ were made for the SE Europe covering ten years period from 01.12.1999 to 30.11.2009 and are driven by the ERA-Interim reanalysis [27], providing the required atmospheric Initial and Boundary Conditions (ICBC) as well as sea surface temperatures. The ERA-Interim boundary conditions can be considered to be of very high quality [27], particularly in the Northern Hemisphere extratropical areas where reanalysis uncertainty is negligible [28]. The simulation domain covers entirely the Balkan Peninsula, a minor part of Italy and a part of Asia Minor Peninsula. The model grid is in Lambert Conformal Conic projection with spatial resolution of $10 \mathrm{~km}$. Hence the previous experiments reveals that time step equal to 25 seconds, and 27 vertical levels are optimal, they are selected for the model integration. The default land surface parameterization method in RegCM4 is the BATS scheme [29]. In the current study, we have used it without the subgridding option. The considered 
planetary boundary layer (PBL) schemes are the one proposed by Holstlag [30, 31] and the University of Washington (UW) $[32,33]$. One of the most significant novelties in RegCM4.4 is the incorporation of the new cloud microphysics scheme (for brevity: M-scheme), proposed by Nogherotto and Tompkins (NT) [34]. EUROCORDEX (http://www.euro-cordex.net/) is the European branch of the international CORDEX initiative, which is a program sponsored by the World Climate Research Program (WRCP) to organize an internationally coordinated framework to produce improved regional climate change projections for all land regions worldwide. Med-CORDEX (https://www.medcordex.eu/) project has been proposed by the Mediterranean climate research community within EURO-CORDEX as a follow-up of previous and existing initiatives. The NT-scheme was released after MedCORDEX experiments started. The cumulus convection (CC) parameterizations include Grell scheme [35] with Arakawa-Schubert (AS) [36] and Fritsch-Chappell (FC) closure assumption [37], Emanuel scheme [38, 39], Tiedtke scheme [40] and Kain-Fritsch scheme [41, 42]. The simulations with Kuo [43] convective parameterization scheme have shown instability and interruptions of the model simulations at some periods, so was not used in the present research.

Thus, the number of the possible combinations, which means RegCM4.4 model set-ups, between 2 PBL schemes, 2 M-schemes and $5 \mathrm{CC}$ ones, is 20 and the performance of all of them have been investigated.

The well-known and freely available for the research community data-base E-OBS version 12.0 of the European Climate Assessment \& data-set (ECA\&D) project [44] is used as reference in the model validation. E-OBS is based only on observations, covers entire Europe and the surroundings, and the version with $0.25^{\circ} \times 0.25^{\circ} \mathrm{reg}-$ ular grid spacing is implemented. It is worthy to emphasize that E-OBS is the standard validation data-base for the EURO-CORDEX.

Hence the multi-annual seasonal mean temperature (referred further for brevity only temperature) and the multi-annual seasonal mean precipitation sum (precipitation) are probably the most important quantities from climatological point of view, the validation study thus far is focussed on them. The E-OBS is on daily basis and RegCM is set to produce output on every 6 hours. Thus, the climatological quantities are calculated after every successive model run with the CDO operators [45]. The detailed results from the validation are presented in [46]. Only the most relevant conclusion will be listed briefly here.

According to the simulated temperature behavior, the models can be divided in two groups those with prevailing warm bias and those with prevailing cold bias. Generally, the biases are more remarkable in the summer than in the winter and are in the interval from about $-3.5^{\circ} \mathrm{C}$ to $3.5^{\circ} \mathrm{C}$, but over the bigger part of the domain typically from about $-2^{\circ} \mathrm{C}$ to $2^{\circ} \mathrm{C}$.

The simulation outcome from all 20 model set-ups produces almost identical picture for the precipitation distribution in winter: The biases are nearly equally distributed and are positive (i.e. the model overestimates the precipitation), with some minor exceptions. The summer biases however, show significant distinction in their distribution and magnitude. They are positive, with some minor exception in Greece. Generally, the precipitation biases however, are very big. Their values vary from below $-100 \%$ to above $160 \%$.

The main conclusions are, first, that the relative weight of the CC-schemes is the biggest and, second, the simulations with the smallest biases are with Grell one with the both closures. The sensitivity of RegCM4.4 to the PBL- and M-scheme seems is significantly weaker. Thus, there are not clear evidences for clear distinction between the model skill with Holstlag or UW PBL parameterization from one side or for over performance of the NT M-scheme in comparison with the default SUBEX. As overall, 7 from 20 model setups show recognizable better performance. They are listed in Table 5.1.

Main aim of the current, second stage of TVRegCM is to "narrow" the selection, i.e. to perform further examination of these 7 model configurations.

Our previous results [46,47] indicate that the biases are bigger in summer. Thus, we will use another approach to assess the model performance in that season, called Taylor diagram [48]. The observation data base is E-OBS version 13.1, but the differences with the version 12.0 are insignificant for our purpose. We will consider the temporal and spatial Taylor diagrams of the normalized (in such a way that the observations standard deviation is equal to the model results with respect to the temporal and spatial variability respectively, for the mean summer daily $2 \mathrm{~m}$ temperature and the mean summer daily rainfall from 2001 to 2008 years. The spatial diagram is constructed from the season average for each location, and the temporal diagram from the spatial average by whole domain on daily basis. The correlation is shown by radial dashed lines, and the 
TABLE 5.1

List of the model set-ups with better (in comparison with the others) performance. The original index and notation is preserved from the first stage of TVRegCM experiment

\begin{tabular}{|c|c|c|c|c|c|}
\hline Index & Notation & ICBC & PBL-scheme & M-scheme & CC-scheme \\
\hline 1 & r11111 & EIN15 & Holtslag & SUBEX & Grell/FC \\
\hline 2 & r11112 & EIN15 & Holtslag & SUBEX & Grell/AS \\
\hline 5 & r11155 & EIN15 & Holtslag & SUBEX & Kain-Fritsch \\
\hline 11 & r12121 & EIN15 & UW & SUBEX & Grell/AS \\
\hline 12 & r12122 & EIN15 & UW & SUBEX & Grell/FC \\
\hline 15 & r12155 & EIN15 & UW & SUBEX & Kain-Fritsch \\
\hline 16 & r12221 & EIN15 & UW & Nogherotto/Tompkins & Grell/AS \\
\hline
\end{tabular}
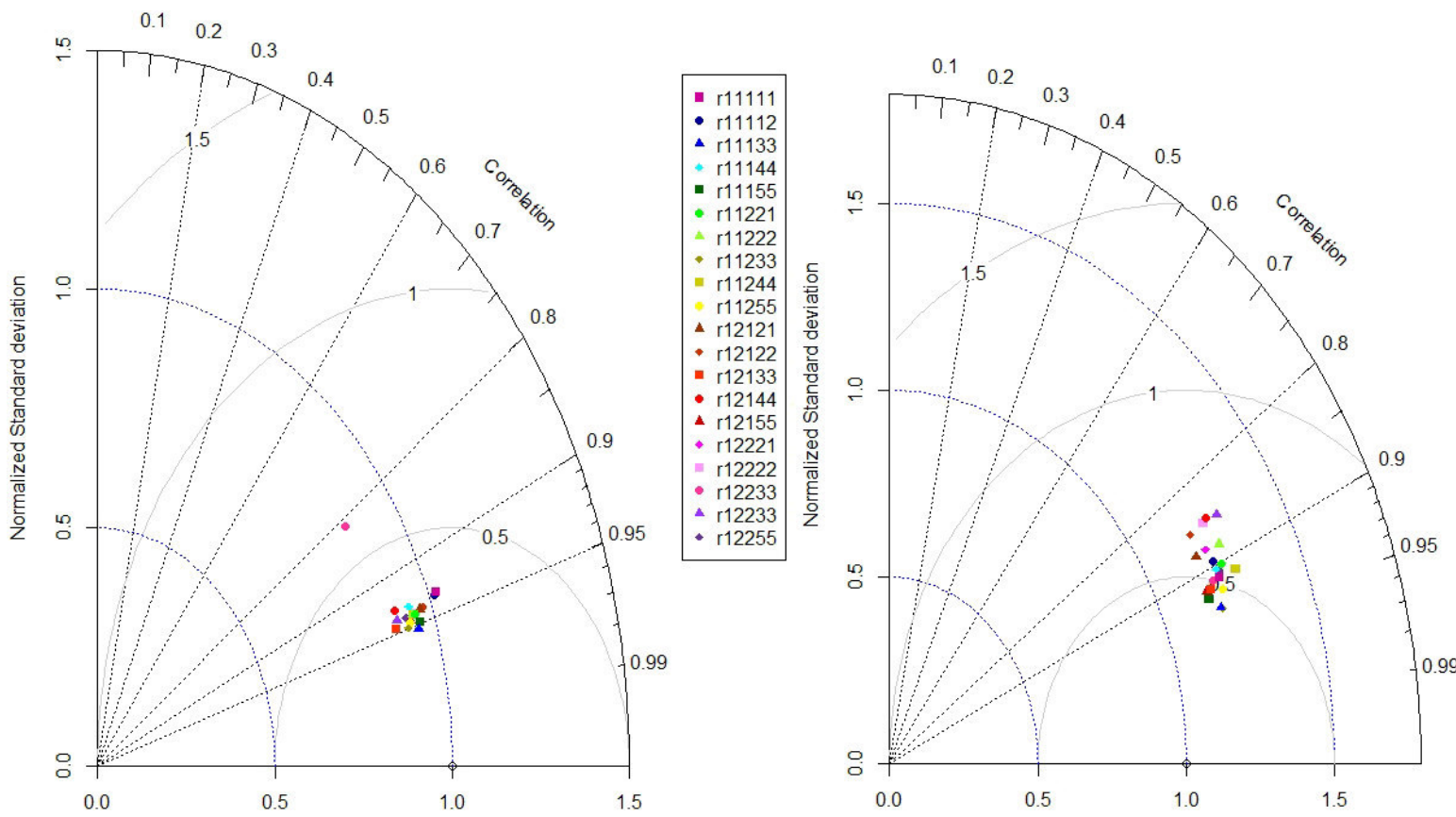

FIG. 5.1. Taylor diagrams for the mean summer daily temperature concerning the temporal (on left) and spatial (on right) variability

normalized standard deviation on the horizontal and vertical axes. The normalization is made in a way that the reference standard deviation is 1 . The lines of centered root mean square difference (RMSD) values are also given.

The Taylor diagram of the mean summer daily temperature for temporal variability is given on the left pane of Figure 5.1. The simulations are depicted by solid color points, and the reference E-OBS data by an empty circle. The normalized standard deviations are below 1.0, except for the cases r11111 and r11112. All simulations except r12222 have RMSD below 0.5. Although relatively small differences, the simulation cases with the slightly better than other cases performances are r11133, r11233, r12133. The Taylor diagram of the mean summer daily temperature concerning the spatial variability is shown on the right pane of Figure 5.1. The correlation coefficient is between about 0.85 and 0.95 . The normalized standard deviation is between 1.0 and 1.5, and the RMSD in most cases is above 0.5. The simulations with the best performance are r11233, r11133 and r11155.

The Taylor diagram with respect of the temporal variability of the mean summer daily precipitation is shown on the left pane of Figure 5.2. The normalized standard deviations are between 0.75 and 1.5. The RMSD 

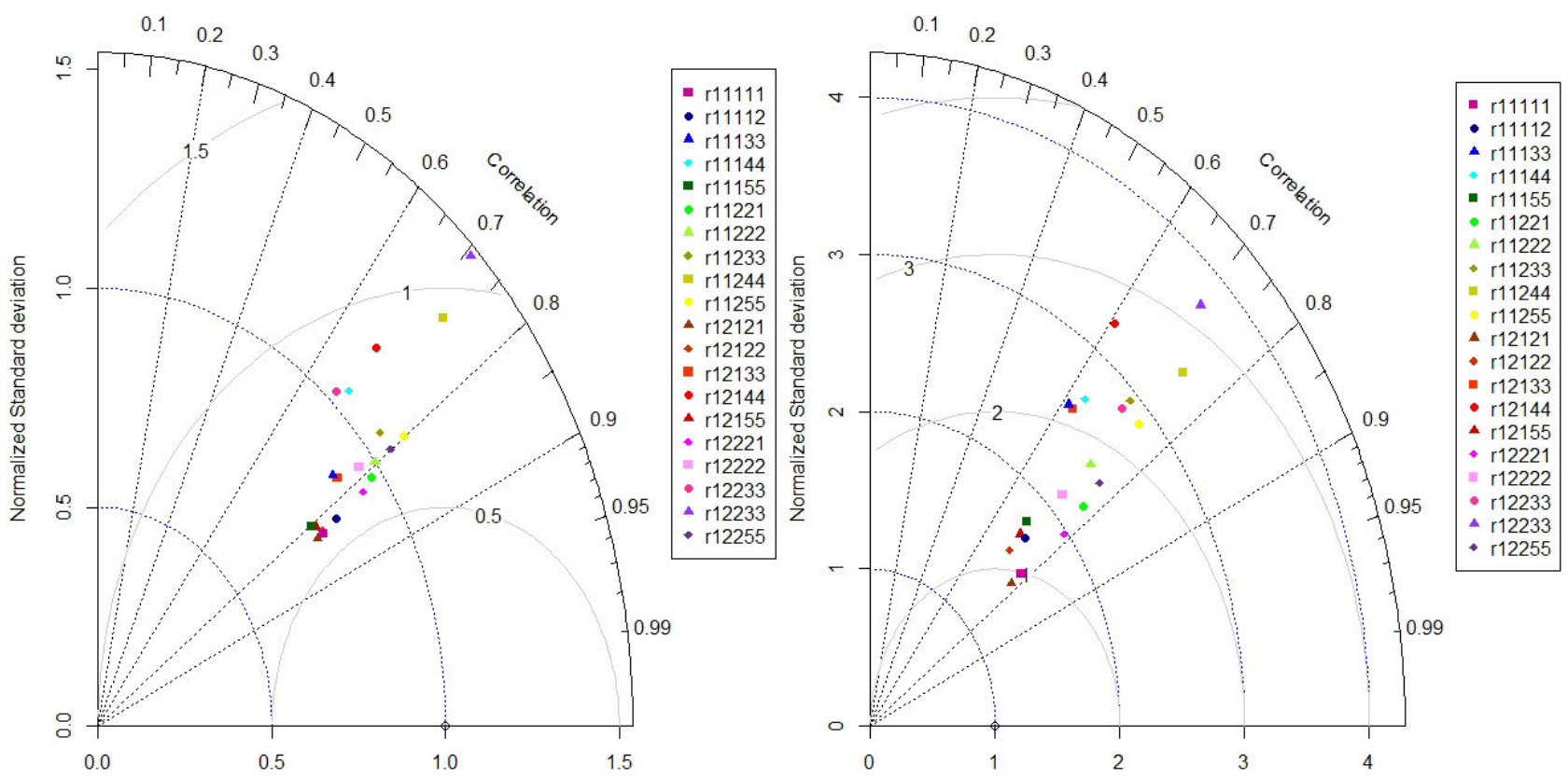

FIG. 5.2. Same as Figure 5.1, but for the precipitation

are between 0.5 and 1.1 , and the correlation is between 0.65 and 0.85 . The simulations results are much more scattered than the ones for the mean daily temperature. The performance of the cases is more distinguishable, and the best ones are r12121, r12122, r11111, r12155 and r11155.

The Taylor diagram of the the mean summer daily precipitation with respect to the spatial variability is shown on the right pane of Figure 5.2. The scattering of the simulation points are bigger than for the mean daily temperature ones, as in the Taylor diagram with respect to the temporal variability. The correlation coefficient is between 0.6 and 0.8. The normalized standard deviation is from about 1.2 to 4.0, and the RMSD is between 1.5 and 2.5. The cases with the best performance are r12121 and r11111, although r12122, r11112, r12155 and r11155 form a cloud of points with slightly worse performance but with normalized standard deviation below 2 .

6. Conclusion related to TVRegCM. The main conclusion of the presented part of the RegCM numerical experiment is that our new test does not reveal single one model set-up that definitely over performs the other considered ones. Nevertheless this exercise was a necessary step forward in the authors' evaluation strategy.

The results of the model temperature field lead us to the following conclusions. The spatial variability is bigger than the temporal one. It is worth to note that the choice of the boundary layer scheme also has some meaning in a spatial variation meaning. The cases with Holstag boundary layer scheme show more resemblance with the observations, than the simulations with UW boundary layer scheme. We can note that the best convective scheme concerning the temperature field is of the Tiedtke.

The spatial variability of the precipitation field is bigger than the temporal one, and from the spatial one for the temperature. The results for the model mean daily precipitation variability on the other hand is as much as about 2 times the reference one and the correlation is weaker than the one for the temperature. Therefore, the model performance is worse for the precipitation than for the temperature. The results suggest that the Grell scheme with FC or AS closures is the best scheme for the precipitation simulation. Although, the Kain-Fritsch cumulus convective scheme with SUBEX moisture scheme and Holstag boundary layer parameterization scheme is also a good case. These results confirm our previous ones [46, 47] that the results for temperature are more spatially homogeneous and the correlation for the temperature field is higher than the one for precipitation. The bigger, in comparison with the temperature, spread of the results on the Taylor diagram for the precipitation demonstrates the bigger sensitivity of this output variable from the parameterization selection and combination 
from different schemes. The results, together with these from the previous stage, are in general agreement with the outcomes in [49] and [50]. In particular, we confirm the outlined in [50] primary importance of the convection scheme. Obviously, many other factors have to be investigated, including:

- It is relevant to investigate the model option to switch the CC-scheme by transition from land to sea and vice versa. It is worth to emphasize that the default setting (and it is explicitly recommended from the RegCM authors'), which is confirmed in [50], is Grell over land and Emanuel over sea.

- It is necessary to perform sensitivity tests over shorter periods, including case studies for warm/cold/ wet/dry years.

- Other output quantities, which are more or less also relevant for many practical applications, such as cloud cover, soil moisture, radiation fluxes, etc should be also considered. Although the availability of independent data-sets, which can be used as reference, seems limited, this further step seems is reasonable.

- The computational efficiency of the selected model set-ups should be estimated.

7. Conclusion. The virtual research environment platform allows to different scientific communities to make research which require big computational and storage resources. A small part of the obtained results from both applications are presented in the present paper, just to demonstrate the opportunity of HPC platforms.

Acknowledgments. Deep gratitude to the organizations and institutes (ICTP, ECMWF, NCEP-NCAR, ECA\&D, Unidata, MPI-M, EMEP, TNO, and all others), which provides free of charge software and data. Without their innovative data services and tools this study would not be possible.

Special thanks to:

- VRE for regional Interdisciplinary communities in Southeast Europe and the Eastern Mediterranean (VI-SEEM), Horizon 2020 project 675121

- The EC-FP7 grant PIRSES-GA-2013-612671 (project REQUA)

- Bulgarian National Science Fund (grant DN-04/2/13.12.2016)

- Program for career development of young scientists, BAS.

\section{REFERENCES}

[1] E. Atanassov, T. Gurov, A. Karaivanova, S. Ivanovska, M. Durchova and D. Dimitrov On the Parallelization Approaches for Intel MIC Architecture, AIP Conf. Proc. 1773, 0700012016 http://dx.doi.org/10.1063/1.4964983.

[2] A. Radenski, T. Gurov, et al Big Data Techniques, Systems, Applications, and Platforms: Case Studies from Academia, in Annals of Computer Science and Information Systems, Volume 8, Proceedings of the 2016 Federated Conference on Computer Science and Information Systems" FedCSIS'16, 2016, pp. 883-888 DOI:http://dx.doi.org/10.15439/ $978-83-60810-90-3$

[3] https://vi-seem.eu/

[4] https://training.vi-seem.eu/index.php/domain-specific-software-and-tools/climate-software-and-tools\# tuning-and-validation-of-the-regcm-tvregcm

[5] https://training.vi-seem.eu/index.php/domain-specific-software-and-tools/climate-software-and-tools\# atmospheric-composition-impact-on-quality-of-life-and-human-health-wrf-cmaq-aciqlife

[6] https://accounting.vi-seem.eu

[7] W. Shamarock, J. Klemp, J. Dudhia, D. Gill, D. Barker, W. Wang, J. Powers A description of the Advanced Research WRF Version 22007 http://www.mmm.ucar.edu/wrf/users/docs/arw_v2.pdf

[8] D. Byun, J. Young, G. Gipson, J. Godowitch, F.S. Binkowski, S. Roselle, B. Benjey, J. Pleim, J. Ching, J. Novak, C. Coats, T. Odman, A. Hanna, K. Alapaty, R. Mathur, J. Mchenry, U. Shankar, S. Fine, A. Xiu, and C. Jang Description of the Models-3 Community Multiscale Air Quality (CMAQ) Modeling System, 10th Joint Conference on the Applications of Air Pollution Meteorology with the A\&WMA, 11-16 January 1998, Phoenix, Arizona, 264-268.

[9] D. Byun And J. Ching Science Algorithms of the EPA Models-3 Community Multiscale Air Quality (CMAQ) Modeling System. EPA Report 600/R-99/030, Washington DC, 1999 http://www.epa.gov/asmdnerl/models3/doc/science/science. html

[10] CMAQ user guide 2006. [Online] Available from: https://www.cmascenter.org/help/documentation.cfm?model= cmaq\&version $=4.6$

[11] CEP Sparse Matrix Operator Kernel Emission (SMOKE) Modeling System, University of Carolina, Carolina Environmental Programs, Research Triangle Park, North Carolina, 2003.

[12] D. Schwede, G. Pouliot, and T. Pierce Changes to the Biogenic Emissions Inventory System Version 3 (BEIS3), Proc. of 4th Annual CMAS Models-3 Users's Conference, September 26-28, 2005, Chapel Hill, NC. 
[13] V. VESTRENG Emission data reported to UNECE/EMEP: Evaluation of the spatial distribution of emissions Meteorological Synthesizing Centre - West, The Norwegian Meteorological Institute, Oslo, Norway, Research Note 56, EMEP/MSC-W Note 1/2001, 2001.

[14] V. Vestreng, K. Breivik, M. Adams, A. Wagner, J. Goodwin, O. Rozovskaya, J.M. Pacyna Inventory Review 2005 (Emission Data reported to LRTAP Convention and NEC Directive), Technical Report MSC-W 1/2005, EMEP, 2005

[15] A. VisschediJk, P. ZANDVELd, H. VAN DER GON A high resolution gridded European emission database for the EU integrated project GEMS TNO report 2007-A-R0233/B, The Netherlands Brunekreef B, Holgate S: Air pollution and health., Lancet 2002, 2007, 360: 1233-1242

[16] Gadzhev, G., Ganev, K., Prodanova, M., Syrakov, D., Atanasov, E., Miloshev, N Multi-scale Atmospheric Composition Modelling for Bulgaria NATO Science for Peace and Security Series C: Environmental Security, 137, 2013, 381-385.

[17] Gadzhev G., K. Ganev, N. Miloshev, D. Syrakov, and M. Prodanova Analysis of the Processes Which Form the Air Pollution Pattern over Bulgaria in I. Lirkov et al. (Eds.): LSSC 2013, LNCS 8353, Springer-Verlag Berlin Heidelberg, 2014, 390-396.

[18] Gadzhev G., K. Ganev, N. Miloshev, D. Syrakov, and M. Prodanova Some Basic Facts About the Atmospheric Composition in Bulgaria - Grid Computing Simulations in I. Lirkov et al. (Eds.): LSSC 2013, LNCS 8353, Springer-Verlag Berlin Heidelberg, 2014, 484-490.

[19] EPA Technical assistance document for the reporting of daily air quality-the Air Quality Index (AQI) EPA- 454/B-09001, US Environmental Protection Agency, Research Triangle Park, North Carolina, Office of Air Quality Planning and Standards, Research Triangle Park, North Carolina 27711, 2009.

[20] Syrakov, D., Etropolska, I., Prodanova, M., Ganev, K., Miloshev, N., Slavov, K. Operational Pollution Forecast for the Region of Bulgaria, American Institute of Physics, Conf. Proc. 1487, 2012, 88-94;

[21] Syrakov, D., Etropolska, I., Prodanova, M., Slavov, K., Ganev, K., Miloshev, N., Luubenov T. Downscaling of Bulgarian Chemical Weather Forecast from Bulgaria region to Sofia city, American Institute of Physics, Conf. Proc. 1561, 2013, 120-132.

[22] Syrakov D., M. Prodanova, I. Etropolska, K. Slavov, K. Ganev, N. Miloshev, and T. Luubenov A Multy-Domain Operational Chemical Weather Forecast System in I. Lirkov et al. (Eds.): LSSC 2013, LNCS 8353, Springer-Verlag Berlin Heidelberg 2014, 413-420,

[23] Leeuw, F. DE, Mol, W. Air Quality and Air Quality Indices: a world apart ETC/ACC Technical Paper 2005/5, 2005, http://acm.eionet.europa.eu/docs/ETCACC_TechnPaper_2005_5_AQ_Indices.pdf

[24] World Health Organization (WHO) Fact Sheet Number 18\%, 2000

[25] World Health Organization (WHO) Health Aspects of Air Pollution. Results from the WHO Project Systematic Review of Health Aspects of Air Pollution in Europe, 2004.

[26] F. GIORGI AND 20 OTHERs RegCM: model description and preliminary tests over multiple CORDEX domains, Clim. Res., $52,2012,7-29$

[27] D. P. Dee, S. M. Uppala, A. J. Simmons, P. Berrisford, P. Poli, S. Kobayashi, U. Andrae, M. A. Balmaseda, G. Balsamo, P. Bauer, P. Bechtold, A. C. M. Beljahe, L. van de Berg, J. Bidlot, N. Bormann, C. Delsol, R. Dragani, M. Fuentes, A. J. Geer, L. Haimberger, S. B. Healy, H. Hersbach, H., E. V. Hèlm, L. Isaksen, P. KÅllberg, M. Köhler, M. Matricardi, A. P. McNally, B. M. Monge-Sanz, J. J. Morcrette, B. K. Park, C. Peubey, P. De Rosnay, C. Tavolato, J. N. ThèPaut and F. Vitart The ERA-Interim reanalysis: configuration and performance of the data assimilation system. Q.J.R. Meteorol. Soc., 2011, 137: 553-597. doi:10.1002/qj.828

[28] S. Brands, J. M. Gutiérrez, S. Herrera And A. S. Cofiño On the Use of Reanalysis Data for Downscaling, J. Climate, $25,2012,2517-2526$.

[29] R. E. Dickinson, A. Henderson-Sellers, And P. J. Kennedy Biosphere-atmosphere transfer scheme (BATS) version 1e as coupled to the NCAR community climate model, Tech. rep., National Center for Atmospheric Research, 1993

[30] A. A. M. Holtslag, E. I. F. DE Bruijn And H.-L. PAN A high resolution air mass transformation model for shortrange weather forecasting, Mon. Wea. Rev., 118, 1990, 1561-1575.

[31] A. A. M Holtslag AND B. A. Boville Local versus nonlocal boundary-layer diffusion in a global climate model, J. Climate, $6,1993,1825-1842$

[32] C. S. Bretherton, J. MCCAA, And H. Grenier A new parameterization for shallow cumulus convection and its application to marine subtropical cloud-topped boundary layers. part I: Description and 1 D results, Monthly Weather Review, 132, 2004, 864-882

[33] H. Grenier And C. S. Bretherton A moist PBL parameterization for large-scale models and its application to subtropical cloud-topped marine boundary layers, Monthly Weather Review, 129, 2001, 357-377

[34] N. Elguindi, X. Bi, F. Giorgi, B. Nagarajan, J. Pal, F. Solmon, S. Rauscher, A. Zakey, T. O’Brien, R. Nogherotto And G. Giuliani Regional Climate Model RegCM User Manual Version 4.4., 2014, p.34, ICTP, Trieste

[35] G. GRell Prognostic evaluation of assumptions used by cumulus parameterizations, Mon. Wea. Rev., 121, 1993, 764-787

[36] A. Arakawa, W. H. Schubert Interaction of a cumulus cloud ensemble with the large scale environment. Part I. J. Atmos. Sci., 31, 1974, 674-701.

[37] J. M. FRITSCh AND C. F. Chappel Numerical prediction of convectively driven mesoscale pressure systems. Part I: Convective parameterization. J. Atmos. Sci., 37, 1980, 1722-1733

[38] K. A. EMANuEl A scheme for representing cumulus convection in large-scale models, J. Atmos. Sci., 48(21), 1991 ,2313-2335

[39] K. A. Emanuel And M. Zivkovic-Rothman. Development and evaluation of a convection scheme for use in climate models, J. Atmos. Sci., 56, 1999, 1766-1782

[40] M. TiEdtke A Comprehensive Mass Flux Scheme for Cumulus Parameterization in large-scale models. Bulletin of the American Meteorological Society, 117, 1989, 1779-1800 
[41] J. S. KAIN The Kain-Fritsch convective parameterization: an update. J Appl Meteorol 43, 2004,170-180

[42] J.S. KAIN AND J. M. FRITSCH A one-dimensional entraining/detraining plume model and its application in convective parameterization. J Atmos Sci 47, 1990 , 2784-2802

[43] R. A. Anthes A cumulus parameterization scheme utilizing a one-dimensional cloud model, Mon. Wea. Rev., 105, 1977, $270-286$

[44] M. R. Haylock, N. Hofstra, A. M. G. Klein Tank, E. J. Klok, P.D. Jones, M. New. A European daily high-resolution gridded dataset of surface temperature and precipitation. J. Geophys. Res (Atmospheres), 2008, p. 113.

[45] CDO 2015: Climate Data Operators. Available at: http://www.mpimet.mpg.de/cdo

[46] Gadzev G., Ivanov, V., Ganev K., Chervenkov H. TVRegCM Numerical Simulations - Preliminary Results, In: Lirkov I., Margenov S. (eds) Large-Scale Scientific Computing. LSSC 2017. Lecture Notes in Computer Science, 2018 vol 10665 , 266-274, Springer, Cham

[47] Chervenkov H. Ivanov, V., Gadzev G., Ganev K. Sensitivity Study of Different RegCM4.4 Model Set-Ups-Recent Results from the TVRegCM Experiment Cybernetics and Information Technologies Vol. 17, No. 5 17-26

[48] TAYLOR K. E. Summarizing multiple aspects of model performance in a single diagram Journal of Geophysical Research, 106, 2001, 7183-7192

[49] S. Kotlarski, K. Keuler, O. B. Christensen, A. Colette, M. Déqué, A. Gobiet, K. Goergen, D. Jacob, D. Lüthi, E. van Meijgaard, G. Nikulin, C. Schär, C. Teichmann, R. Vautard, K. Warrach-Sagi, and Wulfmeyer, V. Regional climate modeling on European scales: a joint standard evaluation of the EURO-CORDEX RCM ensemble. Geosci. Model Dev., 7, 2014, 1297-133

[50] I. Pieczka, R. Pongrcz, K. S. Andrè, F. D. Kelemen, J. Bartholy Sensitivity analysis of different parameterization schemes using RegCM4.3 for the Carpathian region, Theor Appl Climatol, 130, 2017, 1175-1188

Edited by: Aneta Karaivanova

Received: Dec 21, 2017

Accepted: Mar 30, 2018 